\title{
Synthesis of ferroelectric perovskites through aqueous-solution techniques
}

\author{
G. GUZMÁN*, M. A. AEGERTER \\ Instituto de Física e Química de São Carlos, Universidade de São Pãulo, Caixa Postal 369, \\ São Carlos, SP, Brasil and *Chimie de la Matière Condensée, CNRS, Université P. et M. Curie, \\ 75252 Paris, Cédex 05 France \\ P. BARBOUX, J. LIVAGE \\ Chimie de la Matière Condensée, CNRS, Université P. et M. Curie, 75252 Paris, Cédex 05 \\ France
}

The hydrolysis of niobates in aqueous solutions has been applied to the coprecipitation of $\mathrm{PbNb}_{2 / 3} \mathrm{Mg}_{1 / 3} \mathrm{O}_{3}$ leading to a low temperature synthesis of this ferroelectric relaxor ceramic. The effect of hydrolysis conditions - such as the concentration of bases and acids used, their rates of addition and the nature of the precursors salts - is described. The perovskite phase appears after heating at $350^{\circ} \mathrm{C}$ and is obtained as a pure phase at $800^{\circ} \mathrm{C}$ after heat treatment for $1 \mathrm{~h}$. Relaxor ferroelectric ceramics with a high dielectric constant can be obtained by sintering at $1000^{\circ} \mathrm{C}$. The process has been also applied to the synthesis of other relaxor ceramic compositions such as $\mathrm{PZN}\left(\mathrm{PbNb}_{2 / 3} \mathrm{Zn}_{1 / 3} \mathrm{O}_{3}\right)$ and $\mathrm{PFN}\left(\mathrm{PbNb}_{1 / 2} \mathrm{Fe}_{1 / 2} \mathrm{O}_{3}\right.$ ) compounds.

\section{Introduction}

Lead magnesium niobate $\mathrm{PbNb}_{2 / 3} \mathrm{Mg}_{1 / 3} \mathrm{O}_{3}(\mathrm{PMN})$, is a relaxor ferroelectric with a perovskite structure whose high dielectric constant and large electrostrictive coefficient allow interesting applications in the field of capacitors and actuators, respectively. However, its dielectric properties are very sensitive to the processing conditions of the ceramic. In the conventional calcination process using a mixture of oxide precursors [1], pyrochlore phases initially form at a low temperature $\left(T \approx 600^{\circ} \mathrm{C}\right)$. Two of these phases, $3 \mathrm{PbO}-1 \mathrm{Nb}_{2} \mathrm{O}_{5}\left(\mathrm{P}_{3} \mathrm{~N}\right)$ and $2 \mathrm{PbO}-1 \mathrm{Nb}_{2} \mathrm{O}_{5}\left(\mathrm{P}_{2} \mathrm{~N}\right)$, lead upon reaction with magnesium oxide and lead oxide to the formation of pure PMN around $860^{\circ} \mathrm{C}$ and $800^{\circ} \mathrm{C}$ respectively. However, a third pyrochlore structure, $3 \mathrm{PbO}-2 \mathrm{Nb}_{2} \mathrm{O}_{5}\left(\mathrm{P}_{3} \mathrm{~N}_{2}\right)$, also appears and its presence degrades the dielectric properties of the ceramics. This parasitic phase irreversibly forms at higher temperatures due to the loss of $\mathrm{PbO}$.

The crystallization temperature of the perovskite structure can be decreased by using more-reactive precursors which allow a strong reduction in the formation of the deleterious $\mathrm{P}_{3} \mathrm{~N}_{2}$ phase. This has been achieved in a two-step process, described by Swartz and Shrout [2], in which columbite $\mathrm{MgNb}_{2} \mathrm{O}_{6}$ is first prepared and then reacted at $800^{\circ} \mathrm{C}$ with lead oxide:

$$
\begin{aligned}
\mathrm{MgO}+\mathrm{Nb}_{2} \mathrm{O}_{5} & \rightarrow \mathrm{MgNb}_{2} \mathrm{O}_{6} \quad\left(1000^{\circ} \mathrm{C}\right) \\
3 \mathrm{PbO}+\mathrm{MgNb}_{2} \mathrm{O}_{6} & \\
& \rightarrow 3 \mathrm{PbNb}_{2 / 3} \mathrm{Mg}_{1 / 3} \mathrm{O}_{3}\left(800{ }^{\circ}\right.
\end{aligned}
$$

The poor reactivity of $\mathrm{MgO}$ is usually overcome by using a slight excess of $\mathrm{MgO}$ to decrease the amount of the residual parasitic pyrochlore phase [3]. In fact
Goo et al. [4] have shown that, after the first reaction step which occurs at the eutectic temperature of the $\mathrm{PbO}-\mathrm{Nb}_{2} \mathrm{O}_{5}$ system and yields the $\mathrm{Pb}_{3} \mathrm{Nb}_{2} \mathrm{O}_{8}\left(\mathrm{P}_{3} \mathrm{~N}\right)$ pyrochlore structure, $\mathrm{MgO}$ is embedded in a $\mathrm{PbO}$-rich amorphous material which makes the final reaction leading to the pure PMN perovskite

$$
\mathrm{MgO}+\mathrm{Pb}_{3} \mathrm{Nb}_{2} \mathrm{O}_{8} \rightarrow 3 \mathrm{PbNb}_{2 / 3} \mathrm{Mg}_{1 / 3} \mathrm{O}_{3}
$$

difficult. Therefore, a better dispersion of $\mathrm{MgO}$ allows a higher reactivity. It has also been proposed that an excess of $\mathrm{PbO}$ could improve the physical properties of these ceramics through reaction and sintering assisted by the presence of a $\mathrm{PbO}$-rich liquid phase [5]. However, in the case of the columbite-precursor method, the excess $\mathrm{PbO}$ usually remains at the grain boundaries and causes a decrease of the dielectric constant proportional to its amount [4].

The processing of other relaxor ferroelectric ceramics such as $\mathrm{PbNb}_{2 / 3} \mathrm{Zn}_{1 / 3} \mathrm{O}_{3}(\mathrm{PZN})$ and $\mathrm{PbNb}_{1 / 2}$ $\mathrm{Fe}_{1 / 2} \mathrm{O}_{3}(\mathrm{PFN})$ is also a formidable difficulty, as the parasitic pyrochlore phase $\left(\mathrm{P}_{3} \mathrm{~N}_{2}\right)$ is formed even more easily. This has been explained on the basis of thermodynamic parameters, such as the ionic radii and the electronegativity, by Halliyal et al. [6].

For all these relaxor ferroelectric ceramics, it is not clear why the pyrochlore phase forms first or whether the presence of residual pyrochlore phases, such as $\mathbf{P}_{3} \mathbf{N}_{2}$ or $\mathrm{P}_{3} \mathrm{~N}$, at higher temperatures is due to a kinetic or to a thermodynamic effect. These questions remain open.

Optimized dispersion of the precursors can be more easily achieved through the use of solution techniques. The first experiments in this direction were mainly realized using alkoxide precursors [7]. However, the high cost and the difficulty of handling the niobium 
alkoxides make such processes useless for the synthesis of bulk ceramics whose applications to capacitors yield a low added value. Such precursors are more suitable for thin- and thick-film synthesis [8]. More versatile niobium precursors such as oxalates [9] or citrates [10] have also been used, but their processing is difficult because of large, exothermic, weight losses associated with the calcination of organics.

This paper describes the preparation of PMN powders using cheap water solutions of soluble salts such as potassium orthoniobate $\left(\mathrm{K}_{3} \mathrm{NbO}_{4}\right)$, and nitrates or acetates of lead and magnesium. Niobium aqueous species are poorly soluble in water at a $\mathrm{pH}$ below 7 , whereas magnesium and lead hydroxides precipitate above $\mathrm{pH} 9.5$ and 5.5 , respectively. The principle of our process therefore consists in mixing a basic solution (in which the niobate species are soluble) with an acidic solution (in which lead and magnesium salts are soluble). The precursor solutions have been adapted to yield, upon mixing, a solution of intermediate $\mathrm{pH}$ (around 11.0) which allows the coprecipitation of different combinations of the cations. The crystallization sequence of the various structural phases is then described. The powders have been used to prepare PMN ceramics with sintering temperatures as low as $1000^{\circ} \mathrm{C}$ and their dielectric responses are discussed.

In an analysis of the literature, we found previous works were interested in the synthesis of lead niobates from aqueous solutions. These methods were based on potassium metaniobates or orthoniobates [11] or on $\mathrm{K}_{2} \mathrm{Nb}_{2} \mathrm{~F}_{7}$ solutions [12]. But these works have been limited to the analysis of phases formed in the $\mathrm{Pb}-\mathrm{Nb}$ systems at relatively low salt concentrations and upon slow addition of the solutions. For the purpose of application to ceramics, our work has been performed at higher concentrations. In order to achieve the best $\mathrm{Mg}-\mathrm{Pb}-\mathrm{Nb}$ homogeneity, it is also necessary to mix the constituents rapidly by vigorous stirring (except when titrating). Indeed, slow addition usually leads to the phase separation of constituents having very different chemical behaviours [13].

\section{Preparation of $\mathrm{PbNb}_{2 / 3} \mathrm{Mg}_{1 / 3} \mathrm{O}_{3}$ powders and ceramics}

\subsection{Preparation and characterization of the solutions}

The lead and magnesium solutions were prepared by dissolving commercial nitrate powders (Prolabo) of the respective elements in water. $\mathrm{K}_{3} \mathrm{NbO}_{4}$ was chosen as the water-soluble niobate compound. It is synthesized from a mixture of $\mathrm{K}_{2} \mathrm{CO}_{3}$ and $\mathrm{Nb}_{2} \mathrm{O}_{5}$, weighted in an appropriate ratio, which was first ball milled with ethanol for $2 \mathrm{~h}$ and reacted at $740^{\circ} \mathrm{C}$ for $48 \mathrm{~h}$. It is important that the reaction is thoroughly completed, in order to eliminate any residual carbonate ions in the water solution after dissolution. $\mathrm{K}_{3} \mathrm{NbO}_{4}$ is easily dissolved in water up to a concentration of $0.3 \mathrm{M}$ niobium. Only $2 \%$ of the total weight is insoluble and the $\mathrm{X}$-ray pattern of this residue confirms that it contains insoluble $\mathrm{KNbO}_{3}$ (potassium metaniobate).

\subsection{Titration of the niobium solution with an acid}

It is known from the literature that $\mathrm{K}_{3} \mathrm{NbO}_{4}$ hydrolyses in water following the reaction [14]

$$
\begin{aligned}
6 \mathrm{~K}_{3} \mathrm{NbO}_{4}+5 \mathrm{H}_{2} \mathrm{O} \rightarrow & 18 \mathrm{~K}^{+} \\
& +\mathrm{Nb}_{6} \mathrm{O}_{19}^{8-}+10 \mathrm{OH}^{-}
\end{aligned}
$$

This solution provides, for each niobium, three basic equivalents of which $10 \times 3 / 18$ are $\mathrm{OH}^{-}$and $8 \times 3 / 18$ are hexaniobates species. This is demonstrated in Fig. 1a which shows the titration of a $0.3 \mathrm{M}$ solution of $\mathrm{K}_{3} \mathrm{NbO}_{4}$ by $\mathrm{HNO}_{3} 1 \mathrm{M}$. Starting from a high $\mathrm{pH}$ value $(\mathrm{pH}=13.9)$, the $\mathrm{OH}^{-}$ions are first titrated, and then the hexaniobate species precipitate into a niobic acid form $\left(\mathrm{Nb}_{2} \mathrm{O}_{5} \cdot n \mathrm{H}_{2} \mathrm{O}\right)$ in a two-step process. The first of these two steps may correspond to the precipitation of an acid potassium hexaniobate salt, such as $\mathrm{K}_{4} \mathrm{H}_{4} \mathrm{Nb}_{6} \mathrm{O}_{19}$, that transforms into niobic acid upon further addition of $\mathrm{HNO}_{3}$. Thus, no precipitation occurs until the $\mathrm{pH}$ decreases to 11 , and a final $\mathrm{pH}$ as low as 5 is necessary to precipitate niobic acid and avoid contamination with potassium.

Titration of the orthoniobate by lead nitrate yields a similar result although no distinguishable step is observed for the precipitation of $\mathrm{Pb}(\mathrm{OH})_{2}$. The amount of lead nitrate solution necessary to titrate the niobate is in slight excess of the expected $3 / 2$ ratio (Fig. 1b). This is due to the fact that the precipitation of lead nitrate by a hydroxide solution does not lead to the formation of pure lead hydroxide but to an approximate $\mathrm{Pb}\left(\mathrm{NO}_{3}\right)_{2}-3 \mathrm{~Pb}(\mathrm{OH})_{2}$ composition [15]. In other words, not all the lead acts as an acid towards $\mathrm{OH}^{-}$ and hexaniobate species since some lead is precipitated with its nitrate counterion according to

$$
\begin{aligned}
4 \mathrm{~Pb}\left(\mathrm{NO}_{3}\right)_{2}+6 \mathrm{OH}^{-} & \\
& \rightarrow \mathrm{Pb}\left(\mathrm{NO}_{3}\right)_{2} \cdot 3 \mathrm{~Pb}(\mathrm{OH})_{2}+6 \mathrm{NO}_{3}
\end{aligned}
$$

This is demonstrated by the titration curve of lead nitrate by $\mathrm{KOH}$ (Fig. 2). Upon hydroxide addition, immediate precipitation is observed and there is a first neutralization point at $\mathrm{OH} / \mathrm{Pb}=1 / 2$. From the literature, the $\mathrm{Pb}^{2+}$ aqueous ion is hydrolysed (when

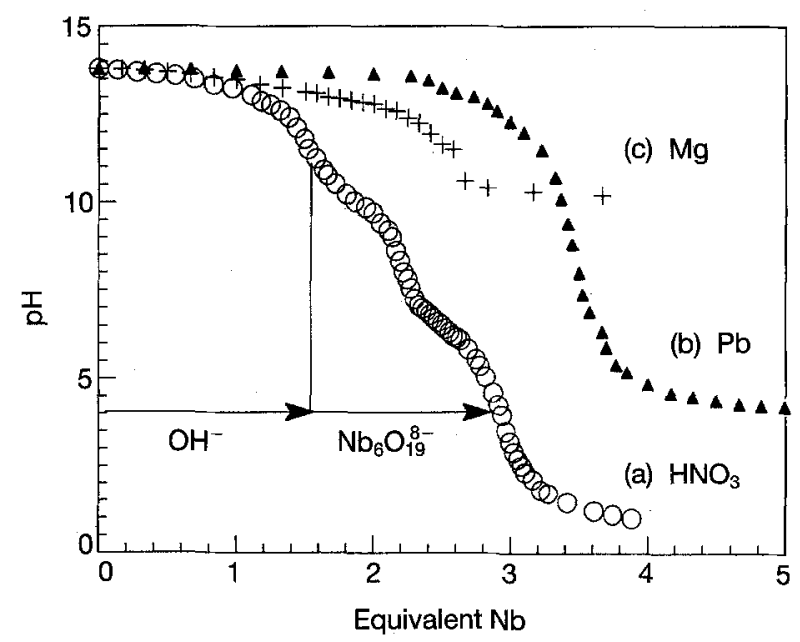

Figure 1 Titration of a $0.3 \mathrm{M}$ solution of $\mathrm{K}_{3} \mathrm{NbO}_{4}$ in water by: (a) $1 \mathrm{M} ; \mathrm{HNO}_{3}$, (b) $0.5 \mathrm{M} \mathrm{Pb}\left(\mathrm{NO}_{3}\right)_{2}$, and (c) $0.5 \mathrm{M} \mathrm{Mg}\left(\mathrm{NO}_{3}\right)_{2}$ 


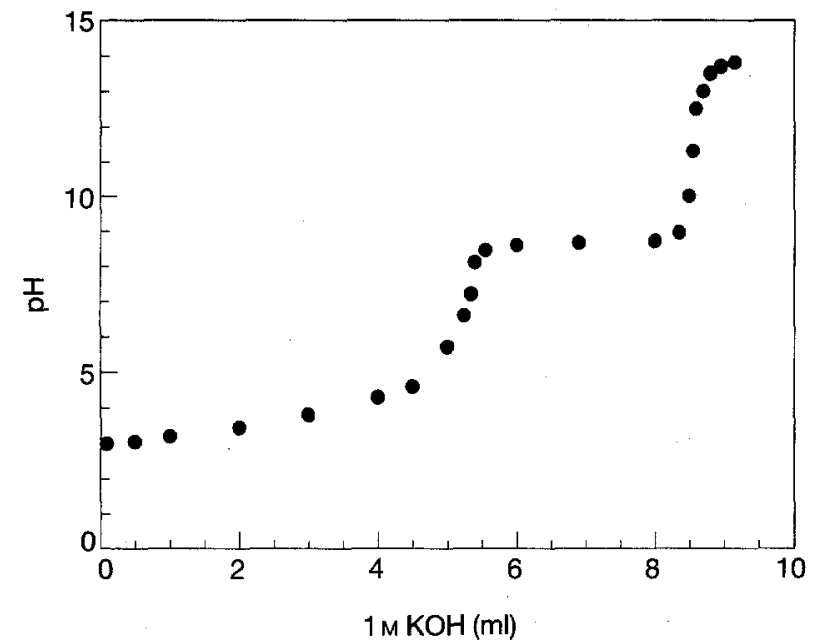

Figure 2 Titration of a $0.5 \mathrm{M} \mathrm{Pb}\left(\mathrm{NO}_{3}\right)_{2}$ solution with $1 \mathrm{M} \mathrm{KOH}$.

increasing the $\mathrm{pH}$ ) in the form of the tetrameric $\mathrm{Pb}_{4}(\mathrm{OH})_{4}^{4+}$ complex [16]. Our titration curve indicates that the lead tetrameric complex is rapidly neutralized by the nitrate counterions and that a precipitation of the basic nitrate salt $\mathrm{Pb}_{4}(\mathrm{OH})_{4}\left(\mathrm{NO}_{3}\right)_{4}$ occurs. Indeed, centrifugation of the precipitate obtained at this first neutralization point removes all the lead from the solution. Upon further addition of $\mathrm{KOH}$, the solid precipitate transforms upon anion exchange with the solution of $\mathrm{OH}^{-}$for $\mathrm{NO}_{3}^{-}$into $\mathrm{Pb}_{4}(\mathrm{OH})_{6+x}\left(\mathrm{NO}_{3}\right)_{2-x}$. But, the substitution may not go to completion. In our titration, the end-point of the titration corresponds to $\mathrm{OH}^{-} / \mathrm{Pb}=1.70$ (i.e. $x=1.2$ ). This titration curve explains the presence of a large amount of nitrates in the precipitate of lead hydroxide as already reported [15].

A titration of the $\mathrm{K}_{3} \mathrm{NbO}_{4}$ solution by a solution of $\mathrm{Mg}\left(\mathrm{NO}_{3}\right)_{2}$ has also been performed. But, the endpoint of the titration is masked by the dissociation of $\mathrm{Mg}(\mathrm{OH})_{2}$ which acts as a buffer at $\mathrm{pH} 10.6$ (Fig. 1c). This indicates that, when the three elements (lead, magnesium, niobium) are used, the final precipitation $\mathrm{pH}$ should not decrease below this value of 10.6 in order to avoid a loss of magnesium.

Thus, upon mixing the niobium, magnesium and lead solutions one expects a mixture of hydroxides and niobates. However, the amount of lead and magnesium corresponding to the PMN composition can only be precipitated with four basic equivalents for each niobium (that is, the composition $\mathrm{Pb}_{1.5} \mathrm{Nb}_{1} \mathrm{Mg}_{0.5}$ corresponds to $2(1.5+0.5)=4$ equivalents $/ \mathrm{Nb}$ ). Since the potassium orthoniobate corresponds to three basic equivalents, at least one $\mathrm{KOH}$ group for each niobium has to be added, theoretically, to the hexaniobate solution before mixing with the acid solution of nitrates. But, $\mathrm{Mg}(\mathrm{OH})_{2}$ is soluble and dissociates in water $\left(\mathrm{p} K_{\mathrm{b}}=11.1\right)$. It is therefore necessary to maintain a final $\mathrm{pH}$ which is high enough to precipitate $\mathrm{Mg}(\mathrm{OH})_{2}$. On the other hand, niobate species do not precipitate at a $\mathrm{pH}$ which is too high. The optimum amount of added $\mathrm{KOH}$ has to be determined experimentally.

The experiment is as follows: $18 \mathrm{ml}$ of a solution containing the appropriate amounts of both lead and magnesium nitrates corresponding to a ratio $\mathrm{Pb} / \mathrm{Mg}=3,([\mathrm{~Pb}]=0.5 \mathrm{M}$ for synthesis of $\mathrm{PMN})$ are rapidly added to $20 \mathrm{ml}$ of a niobium solution $\left(\mathrm{K}_{3} \mathrm{NbO}_{4}=0.3 \mathrm{M}\right.$, with the necessary amount of $\mathrm{KOH}$ added). The precipitation readily occurs. The precipitates are filtered, and the remaining solutions are titrated for niobium (using the precipitation method with $\mathrm{HNO}_{3}$, as described above). When the final $\mathrm{pH}$ is $14,35 \%$ of niobium remains in the solution but only $1.5 \%$ is lost at $\mathrm{pH}$ of 11.5 . No niobium is lost at a final $\mathrm{pH}$ of 10.5 ; but, at this $\mathrm{pH}$, some magnesium is lost in the solution.

Moreover, a large amount of potassium and nitrate ions are found in the precipitate. Their concentration is reported in Fig. 3 as a function of the $\mathrm{KOH} / \mathrm{Nb}$ ratio. Their quantities are far too high to be attributed only to adsorbed species. A better understanding of the presence of these elements comes from the above discussion. A major part of the nitrate was precipitated as the lead counterion whereas potassium was trapped in an acid potassium niobate. These impurities can still be removed upon washing the precipitate with distilled water. However, some magnesium hydroxide may also be lost and the washing is performed by redispersing the precipitate in $100 \mathrm{ml}$ of distilled water and filtering again. This removes the major part of potassium and nitrate as shown in Fig. 3. An alternative method is to rinse the precipitate with a basic solution $\left(\left[\mathrm{NH}_{4} \mathrm{OH}\right]=1 \mathrm{M}\right)$ that does not dissolve $\mathrm{Mg}(\mathrm{OH})_{2}$. As will be shown below, the potassium impurity plays a major role in the crystallization and sintering of the PMN perovskite.

The amount of $\mathrm{KOH}$ to be added is finally adjusted to a molar ratio of $\mathrm{KOH} / \mathrm{Nb}=0.6$ in order to obtain a final $\mathrm{pH}$ of 11 after precipitation. This amount of $\mathrm{KOH}$ corresponds to less than one $\mathrm{OH}$ per niobium. As explained above, in the case of lead-niobate titration, this is attributed to the precipitation of nitratecontaining lead hydroxide and the formation of some residual carbonates. After the washing treatment, chemical analysis yields a composition which corresponds to the PMN stoichiometry.

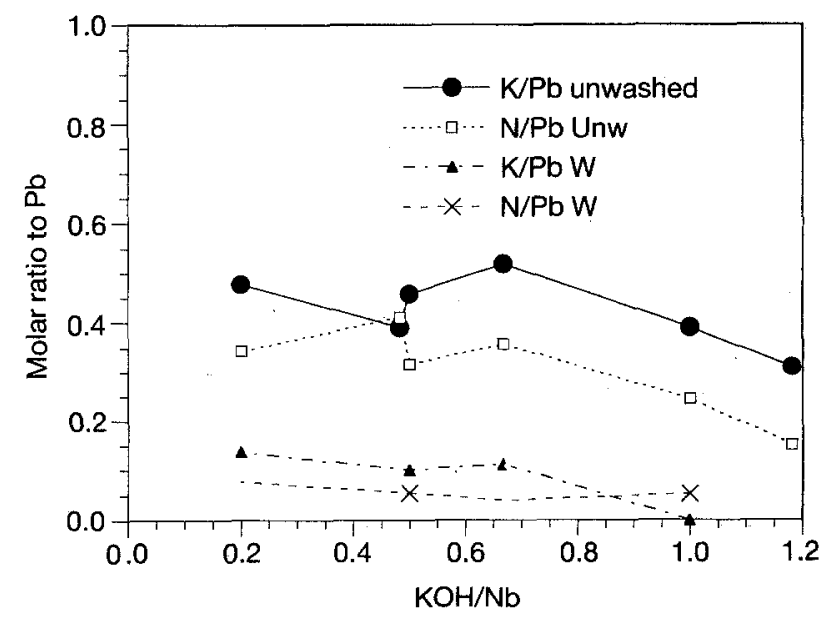

Figure 3 Titration of potassium and nitrate impurities in the precipitate as a function of the $\mathrm{KOH} / \mathrm{Nb}$ ratio for powders washed and unwashed with distilled water: (๑) $\mathrm{K} / \mathrm{Pb}$ unwashed, ( $\square$ ) $\mathrm{N} / \mathrm{Pb}$ unwashed, (A) $\mathrm{K} / \mathrm{Pb}$ washed, and $(x) \mathrm{N} / \mathrm{Pb}$ washed. 


\subsection{Thermal treatment}

Fig. 4 shows the differential thermal analysis (DTA) and thermogravimetric analysis (TGA) performed on a precipitate corresponding to the exact PMN composition. The weight losses are all associated with endothermic peaks. The weight losses occurring between $200^{\circ} \mathrm{C}$ and $450^{\circ} \mathrm{C}$ are associated with the loss of adsorbed water and constitution water coming from the dehydration of metal-hydroxide groups and to the calcination of hydroxides (and also to some traces of carbonates and nitrates) which all decompose below $450^{\circ} \mathrm{C}$.

The progressive crystallization of the material has been followed by X-ray diffraction (XRD) at different temperatures with samples heat treated for $30 \mathrm{~min}$ at the desired temperature (Fig. 5). For the as-dried precipitate, a peak characteristic of an amorphous material is superposed on weak peaks corresponding to traces of $\mathrm{Pb}_{3}(\mathrm{OH})_{2}\left(\mathrm{CO}_{3}\right)_{2}$. For powders heat treated at $350^{\circ} \mathrm{C}$, i.e. after the main weight loss, the $\mathrm{X}$-ray

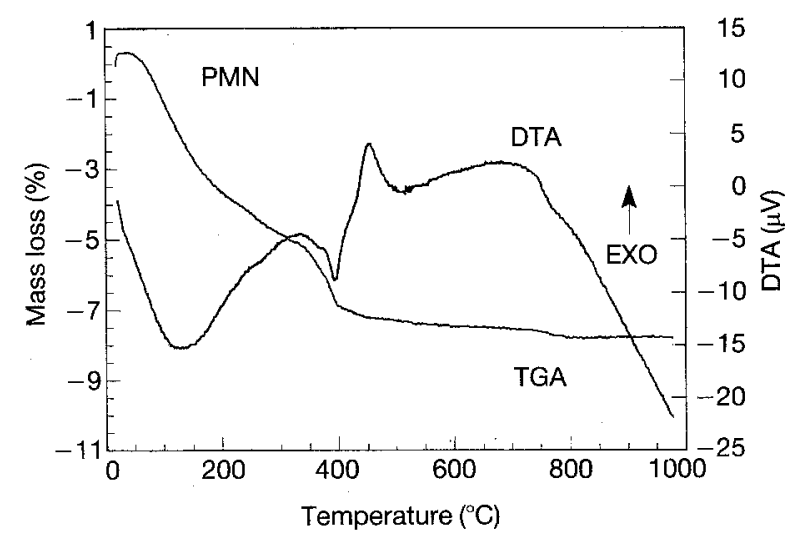

Figure 4 DTA and TGA of PMN powder prepared by the aqueous process.

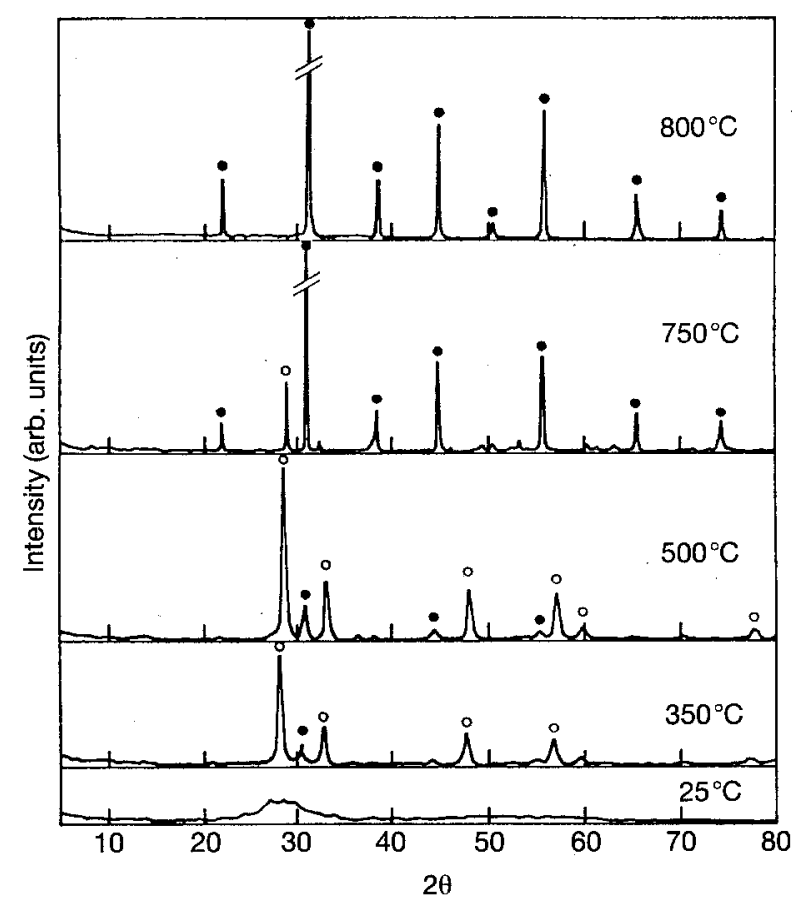

Figure 5 XRD patterns of PMN powder heat treated at various temperatures: (๑) PMN, and (O) $P_{3} N$. pattern is characteristic of the pyrochlore phase $\mathrm{P}_{3} \mathrm{~N}$ already associated with a small amount of the perovskite phase. The percentage of perovskite phase progressively increases until well crystallized, pure, PMN perovskite is obtained at $800^{\circ} \mathrm{C}$.

Depending on the washing conditions, after the final heat treatment at $800^{\circ} \mathrm{C}$, a small amount of impurities may be obtained which consist of either a pyrochlore phase or lead oxide (3\% from the X-ray intensities). But these two impurity phases are never obtained simultaneously. Thorough washing with a solution of ammoniac hydroxide leads to a pyrochlore impurity, whereas in precipitates that have not been washed from the potassium impurity or that have been washed with distilled water the $\mathrm{PbO}$ phase is observed. This is related to slightly different homogeneities in the precipitate which will be addressed in a future work. One hypothesis is that, due to the presence of residual potassium (3\% from the chemical analysis), a solid solution forms between the two perovskite structures $\mathrm{KNbO}_{3}$ and $\mathrm{PMN}$, leaving unreacted $\mathrm{MgO}$ and $\mathrm{PbO}$. However, we have not observed a change in the cell parameters of the PMN perovskite that would clearly indicate a potassium substitution for lead. In the following, we have preferred the methods yielding small amounts of $\mathrm{PbO}$ as the final impurity since this compound acts as a sintering aid.

\subsection{Sintering}

Heat treatment at $800^{\circ} \mathrm{C}$ for $0.5 \mathrm{~h}$ results in $\mathrm{PMN}$ powders composed of grains with a narrow distribution of sizes centred around $2 \mu \mathrm{m}$, as shown in Fig. 6 . The powders were dried at $150^{\circ} \mathrm{C}$ and then pressed into pellets under a pressure of $10 \mathrm{MPa}$. Finally, the material was sintered at $1000^{\circ} \mathrm{C}$ or at a higher temperature. Fig. 7 shows the dielectric behaviour measured at $1 \mathrm{kHz}$ as a function of temperature for a ceramic obtained after sintering at $1050^{\circ} \mathrm{C}$ for $1 \mathrm{~h}$. The temperature behaviour of the dielectric constant and the dielectric loss is typical of the relaxor ferroelectric. A maximum in the dielectric constant of 15000 is obtained at $250 \mathrm{~K}$. The effect of potassium impurities is drastic, as observed in ceramics obtained under the same conditions but without washing of the residual

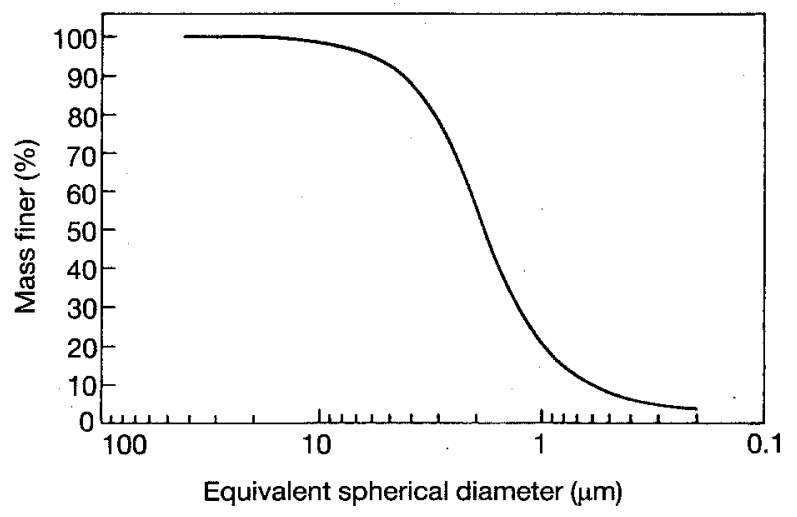

Figure 6 Size distribution of a PMN powder calcined at $800^{\circ} \mathrm{C}$ for $30 \mathrm{~min}$, showing the mass percentage finer than a given diameter. 


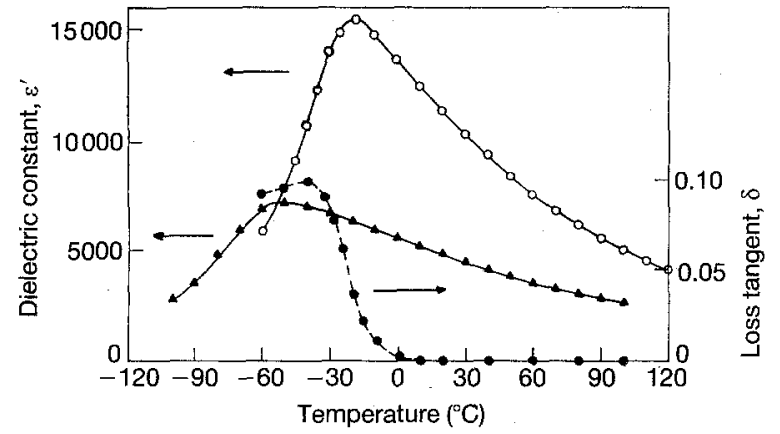

Figure 7 Temperature dependence of: $(O)$ the dielectric constant, $\varepsilon$, and (-) loss tangent, $\delta$, measured at $1 \mathrm{kHz}$ for PMN ceramics (sintering at $1050^{\circ} \mathrm{C}$ for $1 \mathrm{~h}$ ) prepared with a washed precipitate; and ( $\boldsymbol{A}$ ) the dielectric constant of an unwashed powder.

potassium. The low dielectric constant is attributed to the presence of potassium at the grain boundaries of the structure. However, the presence of potassium also affects the temperature of the maximum dielectric constant. This may be attributed to some potassium entering the perovskite structure. A study of the $\mathrm{KNbO}_{3}-\mathrm{PMN}$ phase diagram should be necessary to verify this hypothesis.

\section{Preparation and characterization of other niobate-containing powders}

This aqueous process is quite general and can be applied in principle to the preparation of any niobatecontaining powders as long as it is possible to find water-soluble species of the constitutive elements.

\section{1. $\mathrm{PbNb}_{2 / 3} \mathrm{Zn}_{1 / 3} \mathrm{O}_{3}(\mathrm{PZN})$ powder}

The method for the synthesis of the PZN perovskite is identical to the process described for PMN except that the magnesium nitrate has been substituted by zinc nitrate. After calcination at $800^{\circ} \mathrm{C}$ for $1 \mathrm{~h}$, a wellcrystallized PZN phase is obtained (Fig. 8a). The precipitate was washed with a limited amount of distilled water before the calcination and a small amount of the $\mathrm{PbO}$ phase was observed as the impurity. This $\mathrm{PbO}$ impurity can be easily removed upon washing the calcined powder with a solution of acetic acid, and this is demonstrated by the X-ray pattern of the washed powder (Fig. 8b). However, its presence in small concentrations helps the sintering of the powder. Using the classical methods, the PZN phase is very difficult to obtain without stabilizers starting from the exact stoichiometry [6]. Therefore, the aqueous-solution technique appears very promising in the synthesis of pure $\mathrm{PZN}$.

\section{2. $\mathrm{PbNb}_{1 / 2} \mathrm{Fe}_{1 / 2} \mathrm{O}_{3}$ (PFN) powder}

In this case, the ratio of niobium to the other cations is different from the two precedent compositions and a larger amount of the $\mathrm{KOH}$ base solution should be added in order to obtain a complete precipitation of lead and iron. Good preliminary results have been obtained by mixing a $20 \mathrm{ml}$ aqueous solution of $0.3 \mathrm{M}$

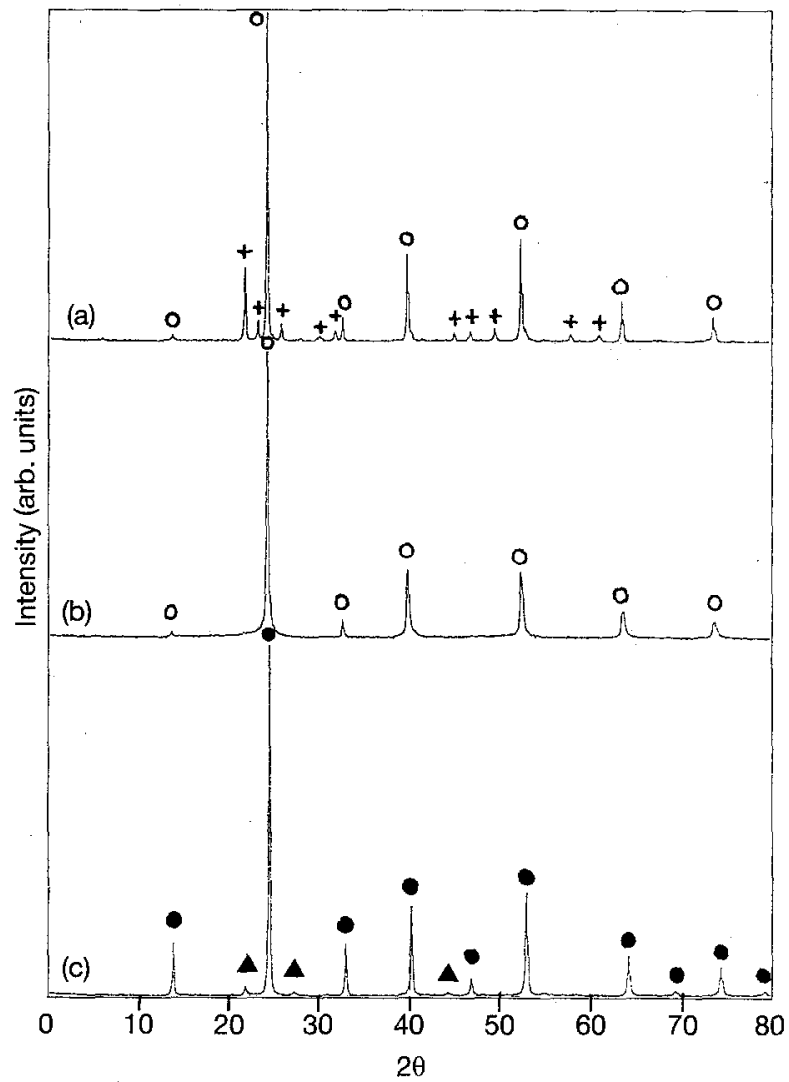

Figure 8 XRD patterns. (a) A PZN powder prepared from the aqueous process and calcined at $800^{\circ} \mathrm{C}$ for $1 \mathrm{~h}$ : (O) $\mathrm{PZN}$, and $(+)$ PbO. (b) The same PZN powder washed with acetic acid. (c) A PFN powder calcined at $800^{\circ} \mathrm{C}$ for $1 \mathrm{~h}$ : (O) PFN, and (A) $\mathrm{P}_{3} \mathrm{~N}$.

$\mathrm{K}_{3} \mathrm{NbO}_{4}$ with a $6 \mathrm{ml}$ solution of $2 \mathrm{M} \mathrm{KOH}$ together with $24 \mathrm{ml}$ of a $0.5 \mathrm{M} \mathrm{Pb}\left(\mathrm{NO}_{3}\right)_{2}$ solution and $12 \mathrm{ml}$ of a $0.5 \mathrm{M} \mathrm{Fe}\left(\mathrm{NO}_{3}\right)_{3}$ solution. A material containing $97 \%$ of the perovskite phase (Fig. 8c) is obtained with pyrochlore structure as the impurity.

\section{Conclusion}

A cheap process based on aqueous solutions has been derived for the synthesis of niobates containing powders such as the relaxor ferroelectric perovskites PMN, PZN and PFN. It is based on the coprecipitation of the oxide precursor obtained after mixing a basic niobium solution, prepared by dissolving orthoniobate $\mathrm{K}_{3} \mathrm{NbO}_{4}$ in water, with acidic aqueous solutions of the other cations.

The $\mathrm{pH}$ of the final solution is an important parameter in the control of the stoichiometry of the composition. Usually, too high a $\mathrm{pH}$ causes a loss of niobium and too low a $\mathrm{pH}$ causes a loss of magnesium, zinc or iron. Potassium and nitrate ions are also coprecipitated, and the precipitates must be washed before calcination without losing magnesium hydroxide. As a result, a spurious $\mathrm{PbO}$ phase $(2-3 \%)$ is practically always found in the resulting powders. It can be removed upon washing the powders with acetic acid or saved for use as a sintering aid.

During the process, the perovskite phase of PMN, PZN or PFN usually appears at $350^{\circ} \mathrm{C}$, after the main weight loss, together with the $\mathbf{P}_{3} \mathbf{N}$ pyrochlore phase. 
The $\mathrm{P}_{3} \mathrm{~N}$ phase completely disappears around $700-750^{\circ} \mathrm{C}$ transforming into a pure perovskite powder with a grain size of about $2 \mu \mathrm{m}$.

The low temperature of this process, associated with the small grain size of the resulting powders, allows the sintering of pure ferroelectric relaxor ceramics at temperatures of the order of $1000^{\circ} \mathrm{C}$. The dielectric response of pure $\mathrm{PMN}$ ceramics sintered at $1050^{\circ} \mathrm{C}$ for $1 \mathrm{~h}$ has been shown to be characteristic of a relaxor ferroelectric with a maximum in the dielectric constant of 15000 at $250 \mathrm{~K}$. Work is underway to optimize the sintering process and to apply this cheap process to other niobate-containing compounds.

\section{Acknowledgements}

This work has been financed by CNPq, Fapesp, Finep and the programs BID-USP and RHAE New Materials, Brazil.

\section{References}

1. M. LEJEUNE and J. P. BOILOT, Ceramics Int. 8 (1982) 99.

2. S. L. SWARTZ and T. R. SHROUT, Mater. Res. Bull. 17 (1982) 1245 .
3. H. C. WANG and W. A. SCHULZE, J. Amer. Ceram. Soc. 73 (1990) 825.

4. E. GOO, T. YAMAMOTO and K. OKAZAKI, ibid. $c 69$ (1986) 188.

5. M. LEJEUNE and J. P. BOILOT, Ferroelectrics 54 (1984) 191.

6. A. HALLIYAL, U. KUMAR, R. E. NEWNHAM and L. E. CROSS, Amer. Ceram. Soc. Bull 66 (1987) 671.

7. H. U. ANDERSON, M. J. PENNELL and J. P. GUHA, Advan. Ceram. Ceram. Powder Sci. 21 (1987) 91.

8. L. FALTER FRANCIS and D. A. PAYNE, Mater. Res. Soc. Symp. Proc. 200 (1990) 173.

9. H. S. HOROWITZ, J. Amer. Ceram. Soc. 71 (1988) 71.

10. M. P. PECHINI, US Patent 3330697 (1967).

11. A. M. GOLUB, NGUYEN CHONG WEN and F. F. GROGORENK O, Russian J. Inorg. Chem. 14 (1969) 607.

12. V. A. TITOVA, I. F. CHEREDNICHENKO and N. G. KISEL, ibid. 12 (1967) 769.

13. P. A. LESSING, Ceram. Bull. 68 (1989) 1002.

14. M. T. POPE and B. W. DALE, Quart. Rev. 22 (1968) 527.

15. J. L. PAULEY and M. K. TESTERMAN, J.Amer. Chem. Soc. 76 (1954) 4220.

16. G. JOHANSSON and A. OLIN, Acta Chem. Scand. 22 (1968) 3197.

Received 17 November 1992 and accepted 24 April 1993 